\title{
Temporary identification style of urban areas
}

\author{
Dmitry Koshkin ${ }^{1[0000-0001-6787-0957]}$, Elena Kudryasheva ${ }^{1[0000-0001-9205-3270]}$, Rafik Khafizov ${ }^{1 *[0000-0001-7242-0459]}$, \\ Rishat Salyakhutdinov 1[0000-0002-6824-7451], and Ainaz Ibragimova1[0000-0002-2786-5309] \\ ${ }^{1}$ Kazan State University of Architecture and Engineering, 420043 Kazan, Russia
}

\begin{abstract}
This article introduces a new concept of 'temporary identification style of urban areas' into design terminology and thoroughly considers the features of the term 'city identification style' and related concepts. Such types of identification style as the temporary style of an event and the permanent style of a place are analysed. Both of the concepts are considered on the example of the city of Kazan, as in 2017 Kazan has applied for World Design Capital (WDC) status. Different identification style elements expressed in the means of visual communication within the urban environment were systematised, such as art objects, small architectural forms, banners, signboards, flags, and unique landscaping. The city's temporary identification style creation and implementation principles were developed. Thereby, each concept corresponds to one of the principles formulated, as follows: urban space refers to the principle of actualisation and temporary thematic renewal of the external appearance of the urban environment; urban infrastructure - to the principle of harmonising the city's subject-spatial environment; cultural life - to the principle of public involvement in creating the urban environment image; the sphere of urban governance and social partnership - to the principle of city management and development through design; informing and information promoting is the principle of implementing design into everyday life.
\end{abstract}

Keywords. City branding, place branding, urban brand identity, city brand identity, urban events.

\section{Introduction}

Currently, the creation of an identification style for the urban environment is a large part of the positive image of a city and its architectural objects, necessary for identifying certain events taking place in the city, and associating the city with certain qualities. The theoretical and practical aspects of creating an identification style for the region and the city have been studied by many scientists. A properly organised process of creating an identification style is a carefully thought out and coordinated system of several creative concepts, integrated into a communication plan, implemented both within a given territory and outside of it. The main customers and managers of the identification style development are, primarily, the government authorities and the business community.

The creation of an identification style for a territory is not a one-time action, but an ongoing process, which is complex and long-lasting. Formation of the image of a region or a

*Corresponding author: raflkhaf1zov@gmail.com 
city involves taking into account the commonality of its cultural, historical and spatial conditions, the ethnic and confessional structure of its population, as well as the need to interact with both its external and internal environment.

The concept of a temporary identification style for a city exists on the border between the identification style of a city and the style of an individual event. As of yet, clear principles that would create a city's unique temporary identification style, emphasising the features of the place, positively affecting its image, and serving as a temporary update of the city's subject-spatial environment, have not been developed.

The aim of this article is to formulate the city's temporary identification style formation principles.

Certain aspects of this problem have been considered in previous works and studies. Various authors have identified and analysed the features of building a city brand on the example of the following cities: Singapore [1], Riga (Latvia) and Aarhus (Denmark) [2], Porto (Portugal) [3] (Fig. 1), Guangdong (China) [4], various European capitals [5], and others.
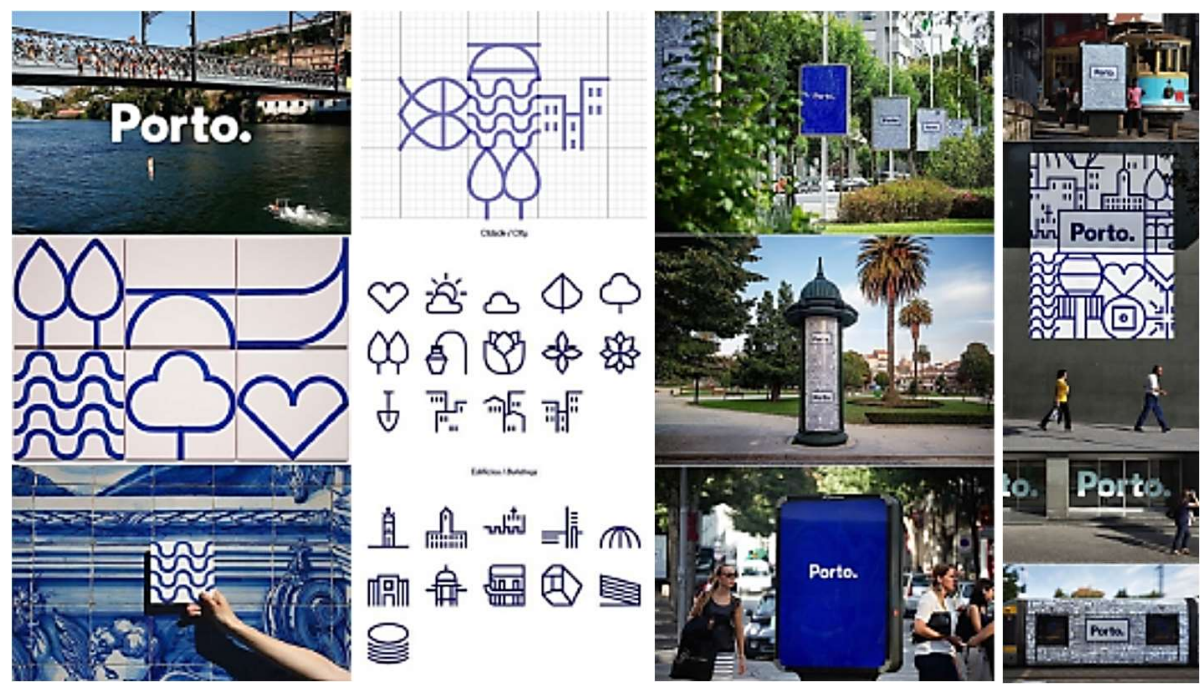

Fig. 1. Building a brand for the city of Porto (Portugal).

Some researchers consider the concepts of 'brand' [6] and 'city brand' [7, 8], analyse the creation of unique places within the concept of 'city brand' $[9,10]$, application of philosophy and branding techniques to urban development [11], the relationship between historicity and relevance [12], the role of the visual identity of the city in the context of graphic design [13], the influence of colour on the formation of a city's brand identity [14], architectural images as a means of conveying brand identity [15], and an analysis of the factors influencing the perception of urban brand logo design $[16,17]$.

\section{Materials and methods}

To consider this concept, classification and typological approaches are used. To reveal the theoretical basis and explain a new concept in scientific practice, the method of comparative analysis of various manifestations of identification styles in environmental design (urban architectural environment, events, public institutions, navigation and visual communication, etc.) was used on various grounds. The objects of the research are the elements for creating the identification style of the urban environment. The subjects of the research are the features for creating a unique temporary identification style of the city. 


\section{Results}

\subsection{Features of the identification style in urban design}

The prerequisites for the emergence of such a concept as «identification style» are considered, namely, the acceleration of the pace of modern life, the emergence of the information environment, "Hollywoodisation of the economy», globalisation, and the economy of impressions. The very concept of identification style is a multifaceted complex system of images that contribute to the recognition and memorisation of the city; it is the uniqueness of the city, reflected in its image.

The formation of the identification style consists of three main stages: defining the idea (theme) of the city, identifying city values, and creating a design. After the formation of the city identification style, work on promoting the idea of the city-style begins. Next, the idea of a city, based on the impression of the city-style «presence» in the urban environment and cultural life, begins to form in the minds of external (tourists, investors, potential residents, etc.) and/or internal (city residents) target audiences.

The graphic elements that make up the basis for the city identification style consist of image, typography, colour, illustration and pattern [18]. The first stage in the creation of visual elements is the formulation of an idea, which becomes the basis for creating a readable and understandable theme. This should, above all, be unique and readable among the variety of existing brands and styles.

Next is the process of developing a logo, which can be represented in the form of a symbol or a word (one or several). After that, font compositions are selected that are suitable in style and complement the required image. Colour also plays an important role in the graphic elements' creation process, as it helps to convey the mood and character of the created image, as well as to encode the necessary information.

Thus, we can conclude that urban communities need to accept global changes in the world and the economy as an inevitable fact that determines the development of territories and to benefit from the urban environment. To achieve this goal, an identification style is created, which is a tool for successful promotion of the city interests, its development and competitiveness.

During the formation of the city identification style, it is necessary to take the main positive aspects of urban uniqueness as a basis, and paying attention precisely to them while formulating the idea of a city, conveying its character and competitive properties. The process of forming the city identification style should not ignore the negative aspects of urban uniqueness, but provide an action plan for their analysis and improvement.

One of the main tools for conveying the idea of a city and introducing the style into the environment is the creation of a visual image, which can become a decisive factor in recognising the city and creating a unique identity.

\subsection{The basic forms of the city identification style of the urban environment}

Such types of city identification attributes as the temporary character of an event and the permanent character of a place are analysed. Both of these are considered by the city of Kazan as an example since in 2017 the city applied for the status of the World Design Capital. This event has a unique style, which becomes a temporary city identification style for a year, while the WDC (World Design Capital) [3] is being held.

If we talk about temporary identification styles of short-term events, then they can be divided into two large groups by their functional and thematic characteristics: cultural and sporting events, each with their own distinctive features 


\subsubsection{Temporary identification style of cultural events}

Cultural events in the life of the city are quite diverse. We have developed a classification of events taking place in the city: scientific events (conferences, forums, and summits), festivals and carnivals (including fairs), exhibitions (including biennials and expositions), musical events and concerts.

Scientific events. In 2017 Kazan hosted the IX International Economic Summit «Russia - Islamic World: KazanSummit». The KazanSummit 2017 agenda touched upon new, but no less relevant areas: social entrepreneurship, ecology, charity, corporate strategies and geoeconomics, cluster politics, tourism, and even Islamic education. The main colours were shades of blue, symbolising the mind. Moreover, the silhouette of the Syuyumbike tower appeared in the logo, which emphasises the importance of holding the summit in Kazan. The identity influenced the main conference hall and the exhibition area, as well as its elements, which were present in the design of banners that adorned the city and the territory near the summit venue.

Festivals and carnivals. «Tasty Kazan» is an annual gastronomic festival on the embankment of Kaban Lake. Along Marjani Street, next to the houses-restaurants for tourists, an information desk was specially installed and decorated in the style of Visit Tatarstan. All temporary buildings, the main stage, and printed materials were made in the same style. The style attracted attention with Tatar motives and expressed special respect for the culture and traditions of Tatarstan. Moreover, this identification style perfectly underlines the peculiarity of the festival - a large number of Tatar dishes.

«Russian Student Spring All-Russian Festival» is a holiday of young talent, which features classical, ethnic and modern dances, throat singing and beatboxing, circus art, theatrical and plastic performances, as well as other traditional and original genres. Every year, a new theme is created for this festival, which uses the main colours of the Russian Youth Union, but at the same time brings something new, characteristic of the host city. For the Russian Student Spring in Kazan, a traditional Tatar tulip was chosen and the silhouette of the Syuyumbike tower. Elements of this theme could be seen both in the interior and exterior. The facades of the main concert venues were decorated using the chosen style.

\subsubsection{Temporary identification style of sporting events}

The visualisation of sporting events is just as important as cultural events to temporary identification style. It also pays great attention to graphical and environmental design. Thus, the whole city is transformed - houses and streets are decorated, the city becomes functional, modern and understandable, and a festive atmosphere is created.

Often, a large-scale information programme is developed for an event, consisting of two stages - the creation of the temporary identification style (designing the image of the event and promoting it all over the world) and direct media coverage.

The graphic package of the temporary identification style for sporting events touches on the field of visual communication. Special attention is paid to the pictogram system. Sporting events held within the city can be classified according to their importance and scale: competitions at the city and regional level; federal competitions; world-class championships and cups;

City and regional level. The Kazan Marathon is an annual race for residents and guests. The temporary identification style included a variety of graphic products, and at the time of the marathon, the part of the city along which the race took place was designed according to the declared concept.

Federal competitions. Kazan hosted the final of the Russian Snowboard Championship in 2017-2018. Some parts of the city were also decorated for this event. 
World-class championships and cups. In 2015, Kazan hosted the World Aquatics Championship - the largest international competition held under the auspices of the International Swimming Federation (FINA). A logo was developed specifically for the event, which featured pictograms of six sports. The execution of the logo was done in watercolour to remain close to the theme of water. The urban environment was filled with elements of the temporary identification style, such as steles, banners, and art objects. Particular importance was attached to the design of sports facilities where the competitions were held. Owing to the Aquatics Championship in Kazan, the Aquatics Palace was built, which is still a significant architectural object to the city.

On the eve of the Olympic Games in Sochi, Kazan hosted the 2013 Summer Universiade. The Universiade emblem was based on the image of a tulip, which is a common element of Tatar ornament, symbolising rebirth. The mascot was a kitten of the winged snow leopard, the symbol of Tatarstan. The city has also been transformed due to a large number of art objects and the construction of a variety of architectural facilities (the Martial Arts Palace, the KazanArena stadium, and the Universiade Village).

\subsubsection{Permanent Identification Style}

The permanent identification style is classified on a territorial basis, in this regard, a place is allocated (a separate territory, including a city or a region), such as a district, a micro-district, a park, a square, a street, or a transport hub. In modern design, two main approaches to stylising a place can be identified: creating a memorable logo using the name/title of the place or a generalised image(s) of the place and its attractions. The first approach includes methods by which a creative graphical expression of the name is found, which carries new meanings and positive associations. The second approach includes methods by which generalised images of a place are presented in «thematic» forms, depicting the main attractions of a given territory.

The permanent identification style of districts and micro-districts directly depends on their functional purpose (historical, residential, business, tourist, family, youth, sports, and creative). This is emphasised by the choice of colours, the character, number and purpose of small architectural forms, and the design of the urban environment as a whole.

Parks, in turn, can be divided into four large groups: urban culture and recreation, theme and entertainment, landscape and botanical gardens, and zoos (including safari parks). In the identification style, this is expressed not only with the help of graphic elements, but also with the choice of materials for creating environmental elements.

Street and square style creation is greatly influenced by its functional purpose, landscape features and culturally significant aspects. This section proposes a division of the types of streets and squares into four groups: transit (the shortest route to the destination), walking, shopping, and historical, each of which may contain elements of an identification style expressed in visual communication means, art objects, small architectural forms, banners, signboards, flags, and unique landscaping [19].

Visual communication related to transport infrastructure and its identification style, is considered. Visual communications are unevenly distributed in the urban environment and are of a different nature depending on the functions. The functional division of visual communication takes place depending on the purpose and location (bus stop, train station, airport, or seaport), this dictates their main stylistic features and character.

Through analysing the forms that the identification style is manifested in the urban environment, several conclusions can be drawn. Firstly, events held in the city are an important tool for creating an identification style of the environment and promoting the interests of the city. In addition, events can be natural (annual events that do not require additional advertising) and special (created in order to draw attention to the city, an occasion 
to create an identification style, to temporarily update the environment). At the same time, they should have the following characteristics: uniqueness, symbolism (which is related to the identity of the city), spectacularity, colourfulness, picturesqueness, and attractiveness for a target audience.

The permanent identification style of a place, on the one hand, is one of the main tools for improving the infrastructure and quality-of-life for citizens, and on the other hand, it becomes an informational occasion, emphasises the uniqueness of a particular place, and attracts more tourists [20]. Regardless of the scope and implementation of the identification style, its function, purpose, and task change little.

\subsection{Principles for urban temporary identification style formation}

Considering the identification styles that were created for the World Design Capitals (Mexico City 2018, Taipei 2016, Helsinki 2014, Cape Town 2012, Seoul 2010, and Turin 2008) [3] and analysing their distinctive qualities, each city's unique stylistic features were identified.

World Design Capital (WDC), appointed every two years by the World Design Organisation (WDO), recognises cities for their effective use of design for economic, social, cultural, and environmental development. Through a year-long programme of events, the designated city is showcasing the best practices in sustainable development focused on urban policies and innovations that improve the quality-of-life. Each of the cities that received the title of the WDC, faced the problem of creating a temporary or permanent identification style for their city.

The main principles that form the temporary identification style are determined, namely: the principle of actualisation and temporary thematic renewal of the external appearance of the urban environment, the principle of harmonising the subject-spatial environment, the principle of public involvement in creating the image of the city's environment, the principle of city management and development through design, the principle of implementation of design into everyday life.

\subsubsection{The principle of actualisation and temporary thematic renewal of the external appearance of the urban environment}

According to the principle of actualisation of the external appearance of the city, temporary and mobile forms, large-scale and human-scale, form a new type of urban spaces - «design spaces», highly comfortable, technically equipped, and dynamic, emphasising the idea and concept of the event. These include the creation of unique architectural projects, landscape design, thematic zoning, and the introduction of identification style into the urban environment.

\subsubsection{The principle of harmonising the subject-spatial urban environment}

Harmonisation of the subject-spatial environment is ensured by the development of urban infrastructure, helping to improve the quality-of-life for citizens. The developed infrastructure not only serves as a background for the formation of the city's identification style, but also becomes its active component. Thanks to the creation of iconic infrastructure projects, the association of the identification style with a comfortable, accessible, and lifefriendly environment is established. 


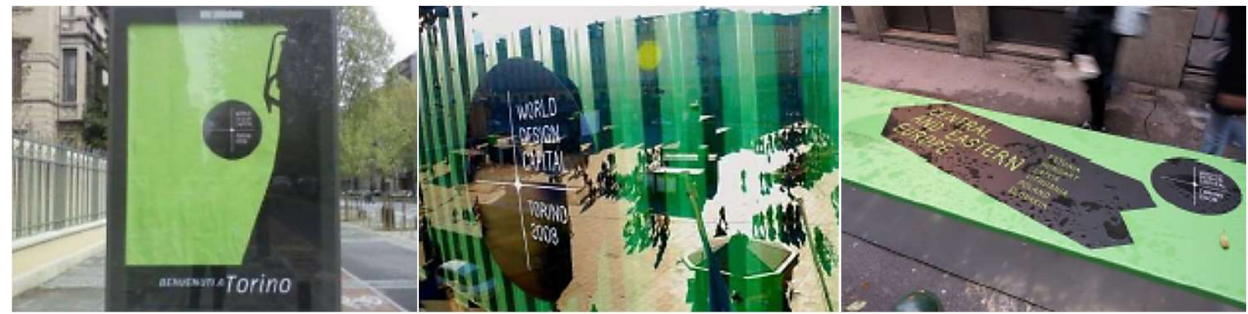

Fig. 2. Turin 2008 World Design Capital.

Turin 2008. The green colour is the «light range» where the human eye is most sensitive and thus able to perceive a wide variety of differences This is why the visual communication of WDC Turin 2008 did not use just one shade of green, based on an accurate colour combination, but rather a wide range of greens that are flexible and fluid. Each shade produces an endless range of sensations. Another green is used in the slogan featured on all supporting materials, followed by the Pantone colour code (or corresponding chromatic percentage) used on a case-by-case basis (Fig. 2). The phrase itself is a reference to the album Another Green World by Brian Eno (1975).

Seoul 2010. The art objects for landscaping, in the form of three cubes, made in the main colours of WDC 2010 with information about the city, country, or upcoming events related to the year of design in Seoul were used on them (Fig. 3).

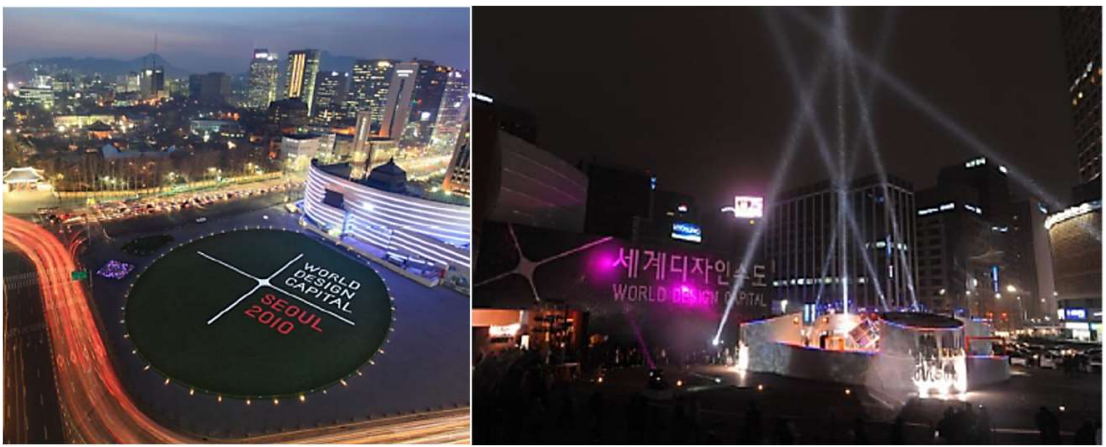

Fig. 3. Seoul 2010 World Design Capital.

Helsinki 2012. Widespread use of illustrations and patterns can be seen created by residents and guests of the city for WDC 2012 (printed materials, banners, window dressing of shops, public spaces, and temporary structures). Created art objects, landscaping elements and thematic zones were designed in the main colours of the event (Fig. 4).
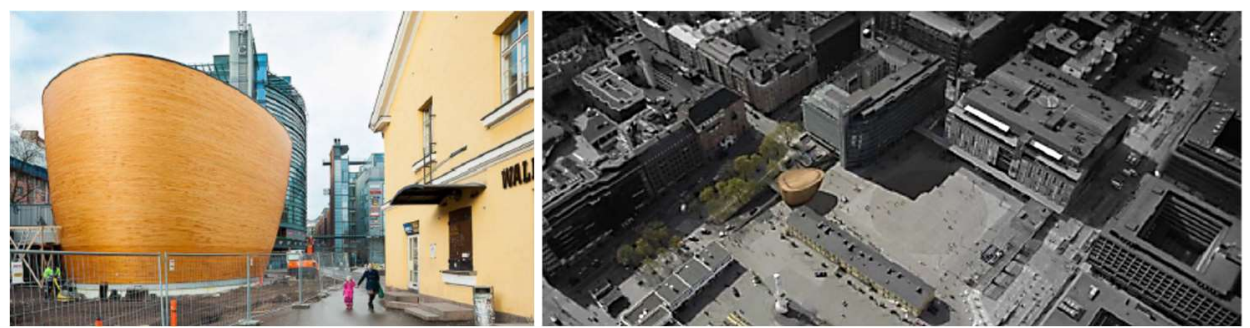

Fig. 4. Helsinki 2012 World Design Capital.

Cape Town 2014. Yellow (Pantone 109-C) was selected as the primary colour for WDC 2014 (Fig. 5). Bright patches of yellow were splattered around the city throughout the WDC 
year. Not only modern buildings were painted in this colour, but also historic buildings received bright and memorable accents of yellow. Elements of visual communication and navigation, posters, trees, paving stones, and public transport - were painted in yellow. As a result, the city received a uniform urban environment style recognisable throughout the world. In addition, it helped bringing together modern and historic architecture. Now, yellow can rightfully be called Cape Town's trademark.

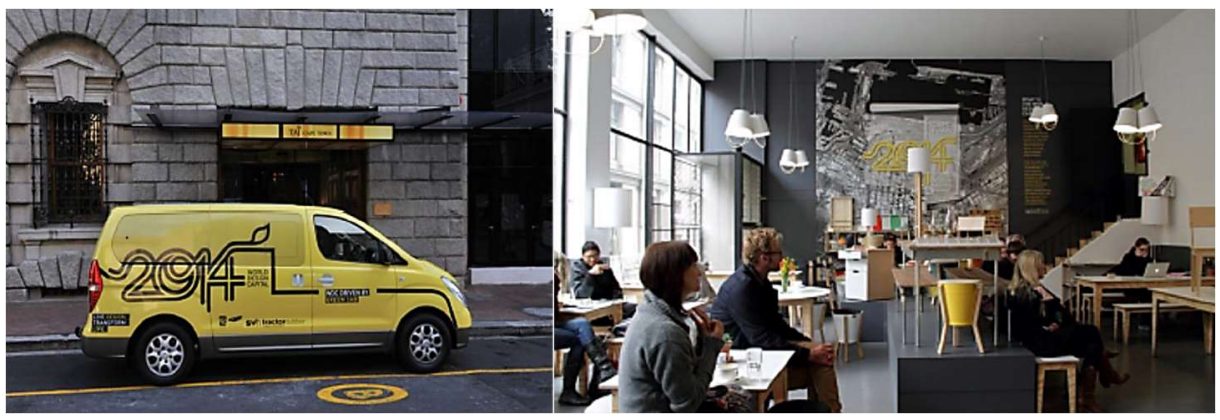

Fig. 5. Cape Town 2014 World Design Capital.

Taipei 2016. All urban design, visual communication means, and colour schemes of public transport were made using one of three variants of symbols or one or more colours of the identification style (Fig. 6).

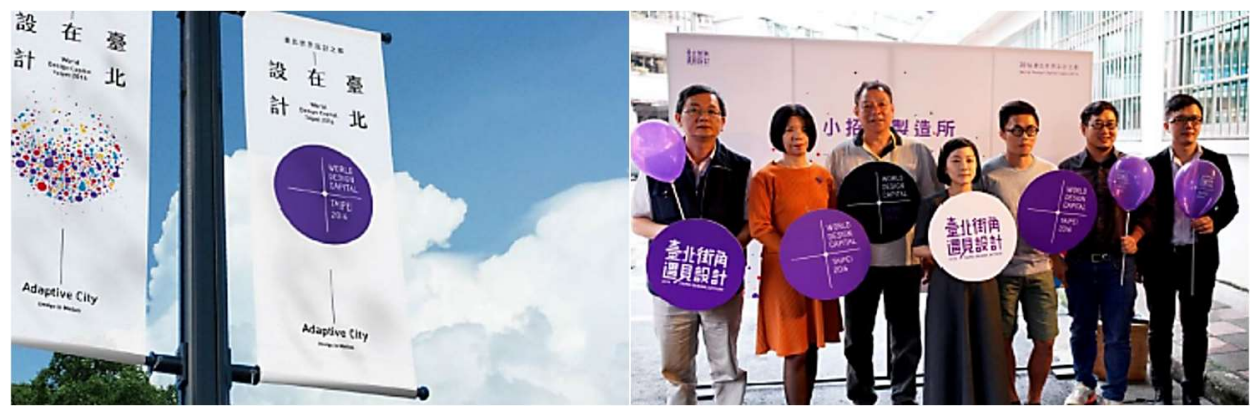

Fig. 6. Taipei 2016 World Design Capital.

Mexico City 2018. Mexico City supported Cape Town's idea of actively integrating the WDC's primary colour into the urban environment, creating a vibrant, memorable look for the city and its architecture. According to this concept, many buildings in the city received updated crimson facades. Moreover, the architectural lighting was updated to reflect the corresponding style.

\subsubsection{The principle of public involvement in creating the image of the city's environment}

Creating the image of the urban environment, according to public opinion, is possible because of talented citizens who are able to solve problems and practice design thinking. Such a stratum of the population should become a driving force for promoting the constant restructuring and evolution of the city, improving the quality of life. Various cultural projects are important for urban identity formation, as they create the symbolic capital of the city the basis for forming the personality and creating the image of the city's environment. 
Turin 2008, «Wall of Design». The residents of Turin had the opportunity to create an art object in the centre of their city by themselves. As part of the acquaintance of the Turin people with the WDC project, everyone was given brochures about the first World Design Capital, Turin. Inside the brochures, there was a sticker (made in the corporate colours and depicting significant objects in Italy and Turin) that could be glued to a special purpose wall. This created an art object 72 meters long, in which every resident of the city took part.

Helsinki 2012, «Helsinki Open Identity». The visual identity of WDC Helsinki 2012 was built around the idea of openness. In a project led by Kokoro \& Moi, workshops were held in Helsinki and Shanghai. As a result, the brand identity featured hundreds of graphic interpretations of the core themes of the WDC by people of all ages, nationalities, and different walks of life. «Ideas Forum», was held in 2010 to prepare the city for the year of the WDC programme. The 'Ideas Forum' was an invitation to a culture of open action and continuity. Thousands of citizens participated in the brainstorming process. About one hundred meetings were held in Helsinki and the municipalities of Espoo, Vantaa, Kauniainen, and Lahti, where more than two thousand ideas were proposed for Helsinki 2012.

Cape Town 2014, «WARD» projects. Thousands of people have been affected and involved in more than 460 projects, the influence of which will continue to shape Cape Town for years to come. «WARD» projects have used design as a tool for citizen participation in 40 collaborative design workshops covering 80 of Cape Town's 111 neighbourhoods, focusing on design for public art, parkland, and the local business district. A total of 2051 people took part in the workshops, which were overwhelmingly rated «fantastic».

Taipei 2016, «Open call». By introducing design thinking and engaging citizens in the design process, WDC 2016 called for collaborative project proposals. The proposed projects had to involve international cooperation to address various urban issues in Taipei «Stir Design». Through this project, the government engaged citizens, designers, engineering firms, and design-related educational institutions to forward their innovative proposals. The main goal was to solve urban problems through design and promote the urban transformation of Taipei. In 2016, the number of participants reached 400000. «Action!» The event was aimed at enhancing citizen participation and knowledge in the design of new signs, navigation aids, booths, schools, and public spaces.

\subsubsection{The principle of city management and development through design}

Managing urban development through design is used to expand design thinking, stimulate urban planning, and also create an interdisciplinary dialogue that is designed to cope with the new challenges of urbanisation and globalisation [21].

\subsubsection{The principle of introducing design into everyday life}

If we talk about innovations and ways to improve human life, then this is largely due to the use of the principle of «introducing design into everyday life», aimed at educating the population in the creative field and explaining its importance and necessity in everyday life, helping in solving their problems by means of design [22].

Following the principles, a unique identification style can be created that will improve the perception of the urban environment and complement the previously formed identity of a particular city. However, it serves as the basis for restructuring the thinking of city residents. The widespread introduction of design into urban, social and political realities, creates a layer of people capable of innovative activities, able to solve the problems that the city faces every day [23]. 


\section{Discussion}

In the course of this paper, a new concept was introduced into design terminology; the term «identification style of the city» and related concepts; for the first time, various types of manifestations of the identification style were systematised in an urban context; the principles of creation and implementation of the temporary identification style of the city were developed for the first time.

Through the course of study, the following conclusions were made: the city identification style is showing uniqueness in the urban environment, fully and correctly reflecting its character. The identification style tells about the city through bright and positive symbols, ideas, and associations that favourably convey all its competitive advantages and features. In the course of creating the concept of identification style, a number of studies and seminars were carried out, target audiences were determined, as well as features of the urban environment, which served as the basis for style formation. After that, work began on the implementation of the identification style in the urban environment in four areas: urban space, urban infrastructure, cultural life, and urban governance. This process is carried out by creating a unique visual image and distributing it throughout the city.

The identification style created in the urban environment can be classified in two ways: the temporary style of the event and the permanent style of the place. Each of these manifestations of style in the city creates its unique image, emphasises the features, forms a picture in the minds of external and internal target audiences.

Analysing the activities carried out within the conceptual framework of the «World Design Capital», we can conclude that they have an impact on all four areas of implementation of the identification style in the urban environment, and serve as a means of informing and educating citizens. Thus, each of the directions corresponds to one of the formulated principles: urban space - the principle of actualisation and temporary thematic renewal of the external appearance for the urban environment; urban infrastructure - the principle of harmonisation of the urban subject-spatial environment; cultural life - the principle of public involvement in creating the image of the urban environment; the sphere of urban governance, social partnership - the principle of city management and development through design; informing and promoting information is the principle of introducing design into everyday life.

The described principles of creating a temporary identification style for a city, in practice, mean various kinds of projects. The more projects there are, the more likely it is to create an identification style, to create a kind of force field that forms a capacious, strong and positive impression of the city, as well as the «correct» (per the concept of style) idea of its identity. All projects carried out in five directions of the city's style formation can be divided into two types: unoriginal, typical for most cities (most of the infrastructure projects) and unique, implemented for the first time and only in this city (projects of culture, information, urban space, and management). In addition, the importance of public participation in the creation of the temporary identification style of the city should be remembered. In this regard, it is necessary to foresee what initiatives, with the participation of residents, can be carried out in the future in each of the five directions.

For each concept of urban temporary identification style, its own unique combination of projects is selected, which creates the effect of the presence of style in the urban environment. Thus, we can distinguish four models of the formation of the city identification style.

The first model is a model, in which the emphasis is placed on the principle of public participation in creating the image of the urban environment (cultural life). This requires a large number of cultural events with the participation of citizens and appropriate infrastructure, which in turn contributes to the emergence of management and spatial projects, as well as information reasons. 
Another model is for creating a temporary identification style for a city based on city management through design. The experience of the World Design Capital cities shows that this helps to solve the problems of the city in an unconventional way, which has a beneficial effect on the urban space, infrastructure, and cultural life, and this, in turn, attracts a large number of tourists, thanks to which the level of information is increased. An infrastructural «megaproject» can become a catalyst for cultural initiatives (exhibitions, fairs, festivals), which, in turn, provoke the creation of appropriate infrastructure, management structures and news articles, thereby forming a brand, and creating a temporary identification style for the city.

\section{Conclusions}

The next model is for creating a temporary identification style of a city, in which projects of public diplomacy and social media catalyse the implementation of the city-style. These projects can be attributed to the principle of implementation of design into everyday life and the principle of public involvement in creating the image of the urban environment, since they demonstrate the ability of citizens to self-organise and participate in creating a unique temporary style of the city.

\section{References}

1. T.C. Chang. Wall dressed up: graffiti and street art in Singapore, City, culture and society 20, (2019). DOI: 10.1016/j.ccs.2019.100329.

2. L. Gunta, M. Birthe. A Tale of Two Re-branded Cities: Riga, Latvia and Aarhus, Denmark, Procedia - social and behavioral sciences 231, (2016). DOI: 10.1016/j.sbspro.2016.09.093.

3. C. Beatriz, M. Patrícia. Residents' involvement in city brand co-creation and their perceptions of city brand identity: a case study in Porto, Place Branding and Public Diplomacy 15 (4), (2019). DOI: 10.1057/s41254-019-00132-8.

4. H. Lu, W. M. de Jong. Evolution in city branding practices in China's Pearl River Delta since the year 2000, Cities 89, (2019). DOI: 10.1016/j.cities.2019.01.026.

5. G. Rico, M. Fernández, A. M. Collado, A. Evangelina. City branding in European capitals: An analysis from the visitor perspective, Journal of Destination Marketing \& Management 7, (2018). DOI: 10.1016/j.jdmm.2016.11.001.

6. M. Riza, N. Doratli, M. Fasli. City Branding and Identity, Procedia - Social and Behavioral Sciences 35, (2012). DOI: 10.1016/j.sbspro.2012.02.091.

7. C. S. Chan, L. Marafa, C. K. van den Bosch, T. Randrup. Starting conditions for the green branding of a city, Journal of Destination Marketing and Management 10, (2018). DOI: 10.1016/j.jdmm.2018.05.006.

8. G. Warnaby. Taking a territorological perspective on place branding?, Cities 80, (2018). DOI: 10.1016/j.cities.2018.06.002.

9. Yu. V. Gorgorova. City brands: identity in the urban environment, IOP Conference Series: Materials Science and Engineering 698, 033030 (2019). DOI: 10.1088/1757899X/698/3/033030.

10. M. Kavaratzis. Place branding: Are we any wiser?, Cities 80, (2018). DOI: 10.1016/j.cities.2018.06.003.

11. H. Lu, Jong, W. M. de Jong, Y. Song, M. Zhao. The multi-level governance of formulating regional brand identities: Evidence from three Mega City Regions in China, Cities 100, 102668 (2020). DOI: 10.1016/j.cities.2020.102668.

12. I. Hassen, M. Giovanardi. The difference of «being diverse»: City branding and multiculturalism in the 'Leicester Model', Cities 80, (2018). DOI: 10.1016/j.cities.2017.06.019. 
13. W. Cudny, R. Comunian, A.Wolaniuk. Arts and creativity: A business and branding strategy for Lodz as a neoliberal city, Cities 100, (2020). DOI: 10.1016/j.cities.2020.102659.

14. Seraphin, Hugues \& Zaman, Mustafeed \& Olver, Sharon \& Bourliataux-Lajoinie, Stéphane \& Dosquet, Frédéric. Destination branding and overtourism, Journal of Hospitality and Tourism Management 38, (2019). DOI: 10.1016/j.jhtm.2018.11.003.

15. V. Visanich, T. Sant. Establishing a creative identity: Rebranding a creative space, City Culture and Society 10, (2017). DOI: 10.1016/j.ccs.2017.04.001.

16. F. Kotsi, M. S. Balakrishnan, M. Ian, R. Thomas Z. Place branding: Aligning multiple stakeholder perception of visual and auditory communication elements, Journal of Destination Marketing \& Management 7, (2016). DOI: 10.1016/j.jdmm.2016.08.006.

17. M. Florek, M. Hereźniak, A. Augustyn. Measuring the effectiveness of city brand strategy. In search for a universal evaluative framework, Cities 110 (6), (2021). DOI: 10.1016/j.cities.2020.103079.

18. S. Mikhailov, R. Khafizov, A. Mikhailova, N. Nadyrshine, L. Nadyrshine. Supergraphics as a project and artistic method in design of a modern city, IOP Conference Series: Materials Science and Engineering 890, 012003 (2020). DOI: 10.1088/1757899X/890/1/012003.

19. M. Belov, S. Mikhailov, A. Mikhailova. Dizajn peshekhodnoj ulicy, (2015).

20. N. Dembich, S. Mikhailov. Dizajn kak sredstvo sozdaniya istoricheskogo znaka v gorodskoj srede (na primere memorial'nogo marshruta princessy Diany v Londone), Mir nauki, kul'tury, obrazovaniya 5 (36), 219-221 (2012).

21. S. Mikhailov. Dizajn sovremennogo goroda: kompleksnaya organizaciya predmetnoprostranstvennoj sredy (teoretiko-metodologicheskaya koncepciya), Avtoreferat dissertacii doktora iskusstvovedeniya, (2011).

22. L. Kuleeva, T. Burova, L. Listovskaya, A. Ibragimova. Features of modern methods of forming embankments, IOP Conference Series Materials Science and Engineering 890, 012005 (2020). DOI: 10.1088/1757-899X/890/1/012005.

23. S. Mikhailov, A. Mikhailova, N. Nadyrshine. Multilinear approach to representing the historical evolution of urban design (industrial and post-industrial periods), IOP Conference Series Materials Science and Engineering 890, 012006 (2020). DOI: 10.1088/1757-899X/890/1/012006. 